\title{
DOI:10.14526/2070-4798-2020-15-2-108-114
}

\section{Analysis of the training session influence in the volleyball section on mental workability and anxiety level of a medical university students}

\author{
Aleksey V. Danilov*, Elina V. Bulanova, Maksim V. Skorb \\ Tver State Medical University, Tver, Russia \\ ORCID: oooo-ooo1-9292-3045, daniloff.aleksey@yandex.ru* \\ ORCID: oooo-Ooo3-2336-3835, elina.bulanova@mail.ru \\ ORCID: oooo-0002-7730-7110, samerlpangel@yandex.ru
}

\begin{abstract}
Being one of the leading elements of a healthy lifestyle, motor activity not only provides a high level of adaptive capabilities of all human body systems, but also helps to eliminate fatigue that arose in the process of mental work. In this regard, motor activity acquires special relevance in relation to student youth. Sport has always attracted the most active part of students, however, when organizing the training process, it must be taken into account that, along with the positive impact of training on the young man's body, it can have a negative impact on thier mental performance. Materials. The paper presents the results of a training session (training unicycle) impact study in the volleyball section on the level of personal (PA) and situational (SA) anxiety, indicators of mental performance (the amount of memory (AM), attention - stability (accuracy) (AA), intensity (IA), concentration (CA) ; the amount of visual information (AVI), the speed of information processing (SPI), the productivity of mental performance (CPMW)) of a medical university students. Research methods. Analysis and synthesis of scientific literature, testing the level of situational and personal anxiety according to the Spilberger-Khanin methodology, testing mental performance indicators by corrective letter tests (tables by V.Ya. Anfimov), statistical processing of the obtained data, analysis and generalization of the research results. Results. The dynamics of the anxiety state during the training session in the volleyball section depends on the length of the game in the team and the level of tactical and technical training of the student. Classes in the sports section of volleyball eliminate fatigue caused by mental stress during the school day, improving the mental performance of medical students.
\end{abstract}

Keywords: students, level of anxiety, mental performance, sports.

For citation: Aleksey V. Danilov*, Elina V. Bulanova, Maksim V. Skorb. Analysis of the training session influence in the volleyball section on mental workability and anxiety level of a medical university students. Russian Journal of Physical Education and Sport. 2020; 15(2): 87-92. DOI:10.14526/2070-4798-2020-152-108-114

\section{INTRODUCTION}

Being one of the leading elements of a healthy lifestyle, motor activity not only provides a high level of adaptive capabilities of all systems of the human body, but also helps to eliminate fatigue that arose in the process of mental work. In this regard, motor activity acquires special relevance in relation to student youth. Researcher Baiguzhina P.A. showed that according to a number of sensory load parameters, the activity of the students' nervous system is evaluated by the first and second degrees of the third tension class $[1$, 2]. In the process of intense mental labor, fatigue occurs faster than in the process of physical labor. It is known that active physical exercises not only eliminate fatigue caused by mental work, but also increase the intellectual abilities of a person [3].
Studies of Russian scientists have shown the effect of different types of physical exercises and types of physical education classes organization on the mental performance of students in secondary and higher educational institutions $[4,5]$. At the same time, a decrease in cognitive performance was found with high debilitating training [6]. Sport, as the desire for self-improvement and "to surpass others, constantly flaming, to be different" (Homer, Iliad: VI, 208; XI, 784), has always attracted and attracts people of youthful age. At the forefront is the problem of meeting the vital needs of the most active representatives of student youth in the desire to play sports and preventing the negative impact of sports training on their mental performance. In this regard, we conducted a study to analyze the impact of a training session in the volleyball section on the 
cognitive abilities and level of medical students anxiety.

The purpose of the study was to analyze the impact of a training session in the volleyball section on mental performance and the level of situational and personal anxiety of medical students involved in the sports development department.

The objectives of the research:

1. To determine the state of mental performance and the level of anxiety in students of a medical university before a training session in the volleyball section.

2. To determine the state of mental performance and the level of anxiety in students of a medical university after a training session in the volleyball section.

3. To analyze the impact of one training session in the volleyball section on the dynamics of mental performance indicators and the level of anxiety in students of a medical university.

MATERIALS AND METHODS

The study involved students of Tver State
Medical University, assigned for health reasons to the main functional group in physical education, engaged in the department of sports improvement in the direction of "volleyball" - 11 people (young men). In the process of processing the test results, they were divided into 3 subgroups: 1 - first year students $(n=2), 3$ months of experience in the team, 2 - 2 year students $(\mathrm{n}=6), 1$ year of experience in this team, 3 - 4 year students $(n=3)$, the experience of playing in this team is 3 years.

Subject of research: level of personal and situational anxiety, indicators of mental performance (memory size, attention - stability, intensity, concentration; amount of visual information, information processing speed, productivity of mental performance).

Research Methods.

1. Testing the level of personal and situational anxiety by the method of SpielbergerKhanin [7]. The criteria for assessing the level of anxiety are presented in table 1.

Table 1 - Criteria for assessing the level of anxiety (score)

\begin{tabular}{|c|c|c|}
\hline \multirow{2}{*}{$\begin{array}{c}\text { Rating } \\
\text { anxiety level }\end{array}$} & personal & Anxiety Scales \\
\cline { 2 - 3 } & $3,5-4,0$ & $3,5-4,0$ \\
\hline very high & $3,0-3,4$ & $3,0-3,4$ \\
\hline high & $2,0-2,9$ & $2,0-2,9$ \\
\hline average & $1,5-1,9$ & $1,5-1,9$ \\
\hline low & $0,0-1,4$ & $0,0-1,4$ \\
\hline very low & & \\
\hline
\end{tabular}

2. Testing individual characteristics of mental performance by corrective letter tests (tables by V. Ya. Anfimov) [8]. Students worked with tables for 5 minutes. The following were determined: a) the amount of memory (AM) - by the total number of scanned printed characters, conventional units (conv. units); b) stability (accuracy) of attention (AA) - according to the number of mistakes made, conv. units; c) the intensity of attention (IA) according to the formula IA = RC: NC (where RC - the number of crossed out printed characters, $\mathrm{NC}$ - the number of printed characters that needed to be crossed out), conv. units ; d) concentration of attention (CA) - according to the formula CA
= IA x AM, conv. units; d) the amount of visual information (AVI) - according to the formula AVI = $0.5936 \mathrm{x}$ AM (where 0.5936 is the average amount of visual information per one printed character), bit; f) information processing speed (SPI) - according to the formula SPI = (AVI - 2.807 x AA): $\mathrm{T}$ (where 2.807 - information loss per one missed printed character, bit, $\mathrm{T}$ - task execution time, sec.), bits / sec; g) the coefficient of productivity of mental work (CPMW) - according to the formula $\mathrm{CPMW}=\mathrm{AM}^{2}$ : $(\mathrm{AM}+$ AA), conv. units Criteria for assessing memory size, stability, intensity and concentration of attention are presented in table 2. 
Table 2 - Criteria for assessing the amount of memory (AM), stability (AA), intensity (IA), concentration (CA) of attention (conv. units)

\begin{tabular}{|l|c|c|c|c|}
\hline \multirow{2}{*}{ Rating } & \multicolumn{4}{|c|}{ Index } \\
\cline { 2 - 5 } & AM & AA & CA & IA \\
\hline fine & $>1000$ & $\leq 2$ & $>1350$ & 1,0 \\
\hline good & $900-1000$ & $3-5$ & $1260-1350$ & $0,92-1,0$ \\
\hline satisfactorily & $700-900$ & $6-10$ & $945-1259$ & $0,85-0,91$ \\
\hline badly & $<700$ & $\geq 11$ & $<945$ & $<0,85$ \\
\hline
\end{tabular}

The study took place in the second half of the autumn semester. The volleyball training session was held after training sessions from 18.30 to 20.00 with a half hour break after training using variable and game methods for performing physical exercises. The density of classes is planned in accordance with the functional and technical level of sectional students preparedness. The lesson consisted of the preparatory part included stretching, general developmental, strength, special and game volleyball exercises. The main part included the development of game situations necessary for technical and tactical training in volleyball, and the final part. Initial testing (in.t.) was carried out before the training session, control (c.t.) - after it. Statistical processing of the obtained data was carried out with the calculation of the Student criterion (t). The critical confidence level of the null statistical hypothesis $\mathrm{p}$ is assumed to be 0.05 .

\section{RESULTS AND DISCUSSION}

The results of the study are presented in tables 3 and 4

Table 3 - Dynamics of the anxiety level and indicators of mental performance in volleyball students during the training session $(n=11)(M \pm \sigma)$

\begin{tabular}{|c|c|c|c|c|c|c|}
\hline \multirow{2}{*}{\multicolumn{2}{|c|}{ Parameter }} & \multicolumn{2}{|c|}{ Test results } & \multicolumn{2}{|c|}{$\begin{array}{l}\mathrm{p}< \\
\text { in relation to } \\
\text { in.t. }\end{array}$} & \multirow{2}{*}{$\begin{array}{c}\text { dynamics } \\
\text { indicators } \\
(\Delta)\end{array}$} \\
\hline & & in.t. & c.t. & $t=$ & $\mathrm{p}<$ & \\
\hline \multicolumn{2}{|c|}{ situational anxiety score } & $1,78 \pm 0,32$ & $2,17 \pm 0,64$ & 1,54 & $>0,05$ & $0,39 \pm 0,66$ \\
\hline \multicolumn{2}{|c|}{ personal anxiety score } & $1,96 \pm 0,4$ & $1,91 \pm 0,52$ & 0,21 & $>0,05$ & $-0,05 \pm 0,71$ \\
\hline \multirow{3}{*}{ attention } & AA, conv. units & $3,56 \pm 1,35$ & $1,44 \pm 1,35$ & 3,14 & $<\mathbf{0 , 0 1}$ & $-2,1 \pm 1,68$ \\
\hline & IA, conv. units & $0,96 \pm 0,02$ & $0,99 \pm 0,01$ & 3,7 & $<0,01$ & $0,03 \pm 0,01$ \\
\hline & CA, conv. units & $713,1 \pm 180,8$ & $872,4 \pm 114,0$ & 2,11 & $>0,05$ & $159,4 \pm 115,9$ \\
\hline \multicolumn{2}{|c|}{ memory size, conv. units } & $742,3 \pm 180,8$ & $883,1 \pm 109,1$ & 1,89 & $>0,05$ & $140,8 \pm 124,6$ \\
\hline \multicolumn{2}{|c|}{ AVI, bit } & $440,7 \pm 107,3$ & $524,2 \pm 64,8$ & 1,89 & $>0,05$ & $83,6 \pm 74,0$ \\
\hline \multicolumn{2}{|c|}{ SPI, bits /sec } & $1,44 \pm 0,36$ & $1,73 \pm 0,22$ & 2,0 & $>0,05$ & $0,3 \pm 0,23$ \\
\hline \multicolumn{2}{|c|}{ CPMW, conv. units } & $738,8 \pm 180,8$ & $881,7 \pm 109,8$ & 1,91 & $>0,05$ & $142,9 \pm 122,9$ \\
\hline
\end{tabular}


More pronounced differences were revealed when comparing the test results between subgroups of different courses students.

Initial testing showed that 2nd and 4th year students have a higher level of anxiety than 1st year students. The differences are statistically significant with respect to personal anxiety. The dynamics of anxiety indicators during the training session in the subgroups was multidirectional. In older students, anxiety decreased, especially significant dynamics was noted in relation to personal anxiety $(t=3.03)$; anxiety in students of the 1st and 2nd year courses increased, and among first-year students more than the second-year students. This situation can be explained by the longer experience of the game in the team of 4 th year students, the insufficient experience of playing 2nd year students and the new unusual situation for 1st year students.

Table 4 - Comparison of the anxiety level dynamics and indicators of mental performance between subgroups $(\mathrm{M} \pm \sigma)$

\begin{tabular}{|c|c|c|c|c|c|c|c|}
\hline \multirow{4}{*}{\multicolumn{2}{|c|}{ Parameter }} & \multicolumn{6}{|c|}{ Comparison subgroups } \\
\hline & & 1 & \multicolumn{2}{|l|}{2} & \multicolumn{3}{|c|}{3} \\
\hline & & \multirow{2}{*}{$\mathrm{n}=2$} & \multirow{2}{*}{$\mathrm{n}=6$} & \multirow{2}{*}{$\begin{array}{c}\mathrm{t}= \\
(\mathrm{K} 1)\end{array}$} & \multirow{2}{*}{$\mathrm{n}=3$} & \multicolumn{2}{|c|}{$\mathrm{t}=$} \\
\hline & & & & & & к 1 & к 2 \\
\hline \multirow{3}{*}{$\begin{array}{l}\text { SA, } \\
\text { conv. } \\
\text { units }\end{array}$} & in.t. & $1,68 \pm 0,2$ & $1,78 \pm 0,5$ & 0,29 & $1,85 \pm 0,4$ & 0,52 & 0,21 \\
\hline & c.t. & $2,58 \pm 0,8$ & $2,24 \pm 0,8$ & $-0,38$ & $1,8 \pm 0,4$ & $-1,0$ & $-0,8$ \\
\hline & $\Delta$ & $0,9 \pm 0,5$ & $0,46 \pm 0,8$ & $-0,63$ & $-0,05 \pm 0,7$ & $-1,28$ & $-0,74$ \\
\hline \multirow[t]{3}{*}{ PA, } & in.t. & $1,38 \pm 0,04$ & $2,0 \pm 0,34$ & $3, \mathbf{1}^{*}$ & $2,28 \pm 0,24$ & $5,3^{* *}$ & 1,1 \\
\hline & c.t. & $1,88 \pm 1,2$ & $2,18 \pm 0,8$ & 0,24 & $1,57 \pm 0,24$ & $-0,26$ & $-1,31$ \\
\hline & $\Delta$ & $0,5 \pm 1,2$ & $0,18 \pm 0,64$ & $-0,25$ & $-0,7 \pm 0,24$ & $-0,97$ & $-2,2$ \\
\hline \multirow{3}{*}{$\begin{array}{l}\text { AA, } \\
\text { conv. } \\
\text { units }\end{array}$} & in.t. & $4,0 \pm 1,8$ & $3,75 \pm 0,8$ & $-0,33$ & $3,0 \pm 1,8$ & $-0,5$ & $-0,55$ \\
\hline & c.t. & $2,0 \pm 3,5$ & $1,5 \pm 1,5$ & $-0,14$ & $1,0 \pm 1,2$ & $-0,28$ & $-0,42$ \\
\hline & $\Delta$ & $-2,0 \pm 1,8$ & $-2,25 \pm 1,7$ & $-0,12$ & $-2,0 \pm 1,2$ & $\mathrm{O}$ & 0,2 \\
\hline \multirow[t]{3}{*}{ IA, } & in.t. & $0,96 \pm 0,01$ & $0,95 \pm 0,02$ & $-0,4$ & $0,97 \pm 0,02$ & 0,77 & 1,11 \\
\hline & c.t. & $0,99 \pm 0,03$ & $0,99 \pm 0,014^{a}$ & 0,03 & $0,99 \pm 0,011$ & 0,21 & 0,43 \\
\hline & $\Delta$ & $0,03 \pm 0,02$ & $0,04 \pm 0,01$ & 0,45 & $0,02 \pm 0,01$ & $-0,46$ & $-1,48$ \\
\hline \multirow[t]{3}{*}{ CA, } & in.t. & $717,0 \pm 144,1$ & $645,9 \pm 260,7$ & $-0,34$ & $800,1 \pm 65,8$ & 0,55 & 1,0 \\
\hline & c.t. & $871,9 \pm 175,1$ & $849,9 \pm 164,4$ & $-0,11$ & $902,8 \pm 121,5$ & 0,16 & 0,41 \\
\hline & $\Delta$ & $154,9 \pm 30,2$ & $204,1 \pm 111,7$ & 0,69 & $102,7 \pm 72,9$ & $-0,87$ & $-1,23$ \\
\hline \multirow{3}{*}{$\begin{array}{l}\text { AM, } \\
\text { conv. } \\
\text { units }\end{array}$} & in.t. & $750,0 \pm 159,3$ & $676,8 \pm 260,7$ & $-0,33$ & $824,7 \pm 66,3$ & 0,45 & 0,94 \\
\hline & c.t. & $886,5 \pm 200,9$ & $861,0 \pm 157,3$ & $-0,12$ & $910,3 \pm 112,4$ & 0,11 & 0,41 \\
\hline & $\Delta$ & $136,5 \pm 41,6$ & $184,3 \pm 124,6$ & 0,58 & $85,7 \pm 78,7$ & $-0,73$ & $-1,1$ \\
\hline \multirow{3}{*}{$\begin{array}{c}\text { AVI, } \\
\text { bit }\end{array}$} & in.t. & $445,2 \pm 94,6$ & $401,7 \pm 154,7$ & $-0,33$ & $489,5 \pm 39,3$ & 0,45 & 094 \\
\hline & c.t. & $526,2 \pm 119,3$ & $511,1 \pm 93,4$ & $-0,12$ & $540,4 \pm 66,7$ & 0,11 & 0,41 \\
\hline & $\Delta$ & $81,0 \pm 24,7$ & $109,4 \pm 74,0$ & 0,58 & $50,9 \pm 46,7$ & $-0,73$ & $-1,1$ \\
\hline \multirow{3}{*}{$\begin{array}{c}\text { SPI, } \\
\text { bits /sec }\end{array}$} & in.t. & $1,45 \pm 0,3$ & $1,3 \pm 0,5$ & $-0,34$ & $1,6 \pm 0,13$ & 0,5 & 0,96 \\
\hline & c.t. & $1,74 \pm 0,36$ & $1,69 \pm 0,3$ & $-0,11$ & $1,79 \pm 0,2$ & 0,11 & 0,41 \\
\hline & $\Delta$ & $0,3 \pm 0,07$ & $0,4 \pm 0,2$ & 0,65 & $0,19 \pm 0,15$ & $-0,81$ & $-1,16$ \\
\hline \multirow{3}{*}{$\begin{array}{c}\text { CPMW, } \\
\text { conv. } \\
\text { units } \\
\end{array}$} & in.t. & $746,0 \pm 157,5$ & $673,0 \pm 260,7$ & $-0,34$ & $821,7 \pm 66,3$ & 0,5 & 0,94 \\
\hline & c.t. & $884,5 \pm 197,4$ & $859,5 \pm 158,3$ & $-0,12$ & $909,3 \pm 113,6$ & 0,12 & 0,41 \\
\hline & $\Delta$ & $138,5 \pm 39,8$ & $186,5 \pm 122,9$ & 0,59 & $87,7 \pm 77,5$ & $-0,75$ & $-1,1$ \\
\hline
\end{tabular}

Note: ${ }^{*}-\mathrm{p}<0.05 ;{ }^{* *}-\mathrm{p}<0.01 ;{ }^{\mathrm{a}}-\mathrm{p}<0.05$ compared with in.t.; in all other comparisons p $>0.05$.

Initial testing made it possible to establish a higher level of mental performance in all indicators for 4-year students and the lowest for 2-year students. Good intensity and stability of attention, poor concentration of attention, memory size is satisfactory in students of 1 and 4 courses and poor in students of 2 courses are registered in all subgroups. We made the assumption that the training load and the amount of information received during the school day is higher for 1st and especially 2nd 
year students. It leads to overwork of the central nervous system and a significant decrease in mental performance by the end of the day. 4-year students have cyclic classes with a lot of clinical practice. Students receive some of the information in the form of knowledge repetition acquired in junior courses.

In the process of training, all students had a positive dynamic in terms of mental performance. The stability and intensity of attention began to correspond to the assessment perfectly, the amount of memory - to the assessment is good. Despite the improvement in concentration of attention, the students' assessment still remained - poorly. Significant differences between subgroups in the dynamics of mental performance indicators. The most pronounced positive dynamics was registered in 2ndyear students. They have more than students of other courses, increased amount of processed visual information, the speed of information processing and the productivity of mental performance. The lowest dynamics of mental performance was found in 4-year students.

\section{CONCLUSION}

Based on the results of the study, we made the following conclusions:

1. During initial testing students of a medical university revealed a low and medium level of situational and personal anxiety, a higher level -in senior students; reduced rates of mental performance were established, especially in 2nd year students.

2. During the control test, an increase in the level of anxiety in younger students and its decrease in older students were noted; most indicators of mental performance improved slightly, concentration of attention remained at a low level.

3. A training session in the volleyball section contributed to the restoration of mental performance depending on the level of its initial decline: a slight increase in those students for whom it was moderately reduced at the beginning of the study, and a significant increase in those students for whom a significant decrease in initial testing. The dynamics of the anxiety state depended on the experience of the game in this team.

Thus, we established a positive impact of training sessions in the volleyball section on the mental performance of medical students and the dependence of the anxiety state dynamics on the length of the game in the team.

\section{REFERENCES}

1. Baiguzhin P.A. Hygienic assessment of the intensity of mental work of students in a situation of testing theoretical preparedness. Vestnik YuUrGU. 2011; 39: 16-18 [In Russ.].

2. Kicha D.I., Drozhzhina N.A., Fomina A.V. Rukovodstvo k laboratornym zanyatiyam: uchebnoe posobie [General hygiene. A guide to laboratory studies: a textbook]. M.: GEOTARMedia. 2010: 288 [In Russ.].

3. Aberg M.A. Cardiovascular fitness is associated with cognition in young adulthood. Proc Natl Acad Sci USA. 2009; 8-06 (49).

4. Bulanova E.V., Osipova V.G., Korshunova L.A., Lebedeva E.A. The influence of various means of physical culture on cognitive and psychomotor indicators of students of a medical university. Pedagogiko-psihologicheskie I medicobiologicheskie problemy fizicheskoj kul'tury I sporta $=$ Russian Journal of Physical Education and Sport. 2019; 14(2): 38-42. DOI: 10.14526/20704798-2019-14-2-38-42 [In Russ., In Engl.].

5. Kadysheva V.A. Assessment of the effect of physical activity on the mental performance of students with different functional interhemispheric asymmetries. Nauchnyj rezul'tat. Fiziologiya. 2017; 3(2): 15-22 [In Russ.].

6. Hughes G., Watkins J., Owen N., Lewis M. Gender differences in knee kinematics during landing from volleyball block jumps. Human Movement Studies. 2007; 53: 1-20.

7. Salci Y., Kentel B.B., Heycan C., Akin S., Korkusuz F. Comparison of landing meaneuvers between male and female college volleyball players. Clinical Biomechanics. 2004; 19: 622-628.

8. Pappas E., Hagins M., Sheikhzadeh A., Nordin M., Rose D. Biomechanical differences between unilateral and bilateral landings from a jump: Gender differences. Clinical Journal of Sports Medicine. 2007; 17: 263-268. 


\section{Submitted: 22.05.2020}

Author's information:

Aleksey V. Danilov - Senior Lecturer, Tver State Medical University, 17010o, Russia, Tver, Sovetskaya str., House 4, e-mail: daniloff.aleksey@yandex.ru

Elina V. Bulanova - Senior Lecturer, Tver State Medical University, 17010o, Russia, Tver, Sovetskaya str., House 4, e-mail: elina.bulanova@mail.ru

Maksim V. Scorb - Student, Tver State Medical University, 17010o, Russia, Tver, Sovetskaya str., House 4, e-mail: samerlpangel@yandex.ru 